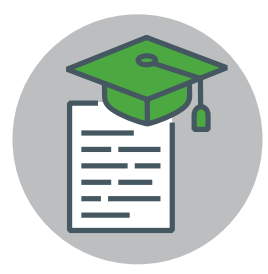

ARTICLE

Anne Holland and Stephanie VierowFields

Space Science Institute

Zachary Stier

Ericson Public Library

Jen Jocz

Education Development

Center

Lindsay Gypin

University of Denver

To cite this article:

Holland, Anne, Jen

Jocz, Stephanie Vierow-

Fields, Zachary Stier, and Lindsay Gypin. 2021

“Community Dialogues

to Enhance Inclusion and Equity in Public Libraries." Journal of Library Outreach and

Engagement 1, no.2: 78-95

DOI:

10.21900.j.jloe.v1i2.856

\title{
Community Dialogues to Enhance Inclusion and Equity in Public Libraries
}

\section{ABSTRACT}

Over the past decade, public libraries have shifted from quiet repositories of knowledge to raucous centers of public engagement. Seeking to fill the educational and social gaps left by other informal education organizations (such as museums and science centers) public libraries are hiring social workers, running accessible makerspaces, developing English language learner (ELL) programs, facilitating hands-on STEM activities, providing information about community resources and social services, delivering summer meals, and much more. But what are the next steps needed to continue this high level of engagement? Through the Community Dialogue Framework (Dialogue), libraries engage with their communities to reach groups not currently benefiting from library services, provide equitable access to resources, develop new partnerships, and —in the time of COVID—began to address the digital divide in their communities. While most library staff agree that providing equitable services is key to their mission, it is perhaps harder to articulate how this can be done. This article provides an overview of the literature that contributed to the development of the Community Dialogue Strategy, and provides actionable advice and lessons learned for conducting Dialogues. An examination of forty public libraries' engagement with and learning from Dialogues was conducted using a qualitative approach and reflexive thematic analysis. An account from a librarian who hosted multiple Dialogues is also presented as a first-person narrative describing their methods and successes using the tool. Library staff at any stage of their community engagement journey can use this paper to understand the benefits and practical considerations for conducting Dialogues, find recommendations for relevant research, understand the basics of conducting Dialogues, and understand the next steps in this emerging component of librarianship.

\section{KEYWORDS}

public library; community; conversation; equity; inclusion

As I pull into the library parking lot, I pass a large group of homeless patrons who very patiently wait in a neat and orderly line for the library to open. It's always a rush to get the best chairs, and this library has some comfy ones! I decide since I'm so early to take a short little nap. I'm awakened to screaming and pounding on my car. The security guard is about to break my window, Narcan in hand, afraid that I'm a patron that has overdosed in the parking lot. He's had to administer Narcan twice in the last month, and it terrifies him every time. I'm here for a conversation about local health needs, to help the library identify like-minded organizations in the community they can reach out to. Before I'm even in the door, I get a lesson about dire health concerns for the community's large homeless population, that the library faces every day in addition to their packed program schedule.

-Anne Holland, personal memo, 8/30/2019 
$\mathrm{T}$ The above interaction occurred before a Community Dialogue (hereafter referred to as simply "Dialogue") at a Colorado library. The Dialogue was part of the Discover Health/Descubre la Salud traveling exhibition (funded by the National Institutes of Health and ran by the University of Denver Anschutz Medical Campus), which provided Colorado libraries with engaging, relevant, and useful health information for their patrons. As evidenced by the security guard's quick response, this library was already aware of specific local health concerns, but the purpose of the Dialogue was to go beyond awareness and reactive planning to identifying organizations in the community that could contribute their efforts and benefit from the work the library was already doing.

The success of the Discover Health Dialogues led the Space Science Institute to expand Community Dialogues, with funding from the National Institutes of Health, NASA, and the National Science Foundation (NSF). With each new Dialogue within this program there was an increase in participants, and more importantly, of diverse participants. Word spread that someone was listening. The project team/authors realized the potential these conversations had to leverage various education and evaluation frameworks to best make use of participants' time and expertise.

Community Dialogues are informal, flexible conversations between library staff, leaders in the local community, and key stakeholders (Holland and Dusenbery 2018; Holland 2016). Unlike focus groups that address a specific service or idea, Dialogues are more openended conversations that solicit informed opinions on the services community members want or need, allowing for flexible and iterative conversations. Dialogues can highlight a host of issues and concerns for the libraries' communities, including access to STEM programming, social justice issues, or environmental concerns. Dialogues transcend current library offerings and the desires of the most // Through the Community Dialogue Framework (Dialogue), libraries engage with their communities to reach groups not currently benefiting from library services, provide equitable access to resources, develop new partnerships, andin the time of COVID—began to address the digital divide in their communities. // active patrons by reaching out to populations who are not using library services, or who may not even feel comfortable walking in the door.

This article provides a review of the literature and research which contributed to the development of the Dialogue framework by the Space Science Institute, a first-person narrative from a public librarian who frequently uses Dialogues, an in-depth discussion from project evaluators of results from Dialogue research and evaluation (including themes identified through case studies, interviews, and observations), and plans and recommendations for future research. When framed around enhancing STEM (science, technology, engineering, and math) programming for the community, Dialogues also empower libraries in their partnership and relationship building.

\section{Literature Review}

Equity in Public Libraries. Dialogues seek to connect public libraries to their communities, and to ensure services being provided are well matched to the needs of the community. According to R. David Lankes (2012), "Bad libraries build collections. Good libraries build services. Great libraries build communities." Public libraries operate at the intersection of knowledge, service, and community. They provide free access to books, learning opportunities, programs, job services, and a safe place to rest (American Library Association 2015). Libraries are a conduit to information, encouraging social inclusion 


\section{Community Dialogues to Enhance Inclusion and Equity in Public Libraries, continued}

and equity, fostering civic engagement and community involvement, and contributing to the economic vitality of communities (American Library Association 2015). Our information-focused society uses access to technology and information as a gate-keeping mechanism, preventing individuals who do not have access or knowledge from accomplishing the most basic tasks (Pew 2013). Libraries offer internet connection for job seekers, tools for homeless patrons to fill out social services paperwork, and English language services for immigrants as they acclimate to their new environments (Usherwood 2016). Public libraries are often the only option for free internet in small and rural communities where broadband is still not universal (Real, Bertot, and Jaeger 2014).

In addition to providing basic information and internet services, libraries increasingly consider the intersections of their patrons' identities. This may include building collections and programs from an indigenous perspective (Thorpe and Galassi 2018), addressing the social determinants of health (Whiteman et al. 2018), providing avenues to combat food insecurity (Williams, Freudenberger, and Fesemyer . 2019), or even placing social work services in residence at public libraries (Johnson 2019).

Equity is an important focus in public libraries, as they continue to work with, rather than just for, their communities. However, there are still challenges to overcome. Libraries hosting technology and makerspace programs encounter barriers when patrons feel like they do not know enough to participate; bilingual storytimes remain empty when Spanish-speaking patrons feel unwelcome; potential volunteers avoid sharing their skills because they do not know the wide breadth of library programs. Addressing these inequalities will come from understanding, acceptance, and engagement with these communities through conversations (such as Dialogues) and outreach (Shtivelband, Wallander-Roberts, and Jakubowski, 2016).

Community Conversation in Libraries. The literature on community conversation in public libraries reveals several themes, the most relevant being that libraries are trusted nonpartisan centers who facilitate communitybuilding between various underserved and privileged groups. Lor (2018) argues that "libraries provide continuing access to the records of our time. As a nonpartisan space, a bit boring perhaps, but trustworthy, the library provides a space for reflection, a haven for civility and rationality, and a home for contrarian thinkers" (317).

Research on engagement of various minority populations through conversation-based library programming has been completed with veterans (Brown 2015), racial minorities (Everett 2018), persons experiencing homelessness (Africawala 2015; Honisett, Short, and Schwab 2018), and recent immigrants (Johnston 2016; Johnston and Audunson 2019). Several studies note that while conversation-based library programming has clearly been successful, empirical evidence is needed to understand why this is so (Johnston 2016). The Research and Evaluation section of this paper describes some progress in this area, and the personal account from Dr. Zachery Stier of the Erickson Public Library provides examples of recent Dialogue work and introduces promising engagement techniques.

Methods used to facilitate conversation-based library and museum programming include the Harwood Method (American Library Association 2015), the Museum of Science Boston Community Conversation series (Museum of Science 2021), Intergroup Dialogue (Damasco 2019), conversation-based programming and Intergroup Contact Theory (Johnston 2016; Johnston and Audunson 2019), Coffee and Conversations (Africawala 2015; Honisett, Short, and Schwab 2018), and Silent Dialogue (Everett 2018). Each of these 
conversation methods was created to address specific concerns either in the community or the hosting venue. For example, Intergroup Dialogue "intentionally surfaces issues of power, privilege, and systemic oppression around social identities as being central to both the content and process of dialogue" (Damasco 2019, pg. 14). Similarly, the Coffee and Conversations program has the aim of "providing a space for open dialogue on topics that unite us, rather than divide us" (Africawala 2015).

By far the most commonly used conversation method in public libraries is the "Libraries Transform" initiative that was developed by the Harwood Institute for Public Innovation (Harwood Institute) in collaboration with the American Library Association (American Library Association 2015). Libraries Transform is a public awareness campaign that includes a Community Conversation Workbook created by the Harwood Institute to encourage libraries to "turn outward" to authentically engage with community members (American Library Association 2015).

All these methods have contributed to the Community Dialogue model described in this paper, and the authors would like to stress that each method can be extremely beneficial if the library and community have the appropriate time, resources, and support to manage it. The Dialogue framework is meant to be an engaging and flexible process that can complement other, more in-depth, programs (such as Harwood), or more informal methods (such as Conversation Cafes). In short, there is no one "right" answer to using Dialogue in community engagement, and we encourage library staff to consider using the flexible Dialogue model as a first step, and potentially incorporate other methods as they get deeper into the work.

Empowerment Evaluation and Participatory Action Research. The concepts of Empowerment Evaluation (Fetterman 1994) and Participatory Action Research (Lewin 1946) have greatly influenced and inspired the development of the Community Dialogue framework. Rather than relying on outside entities to visit an in-situ environment, pass their judgment, and leave, these methodologies rely on the skills, knowledge, and relationships of local participants to build an understanding of community which will directly and positively impact that community, not solely other researchers. This is not to say that the Dialogue model is an evaluation or research activity, simply that the theoretical framing of these models is well suited to the intentions of library staff conducting these activities.

Empowerment Evaluation, characterized by a collaborative methodology, focuses on self-determination in an evaluative setting (Patton 1997; Fetterman 1994). It formulates relationships between stakeholders, evaluators, and the community through evaluative concepts and techniques that create a synergistic approach to projects or programs where all parties are actively engaged (Secret, Jordan, and Ford 1999; Fetterman et al. 2017; Fetterman and Wandersman 2005). This approach also shifts authority from the evaluators to the interested groups to choose criteria, collect the data, and disseminate the reports (Stufflebeam 1994; Everhart and Wandersman 2000; Fetterman et al. 2017). This process "is explicitly designed to serve a vested interest" (Fetterman 1994). We see this as a key component of Dialogue. The purpose of these conversations is not necessarily to hear all sides, or to make sure everyone is receiving the same services. They are explicitly intentional about digging deep into community challenges and identifying groups who need extra support and resources.

Similar to Empowerment Evaluation, Participatory Action Research puts the stakeholder (library staff or community member) in the driver's seat of assessment. When Lewin first wrote of this in the context of racial tensions in 1946, he noted that "There exists a great amount of good-will, of readiness to 


\section{Community Dialogues to Enhance Inclusion and Equity in Public Libraries, continued}

face the problem squarely and really to do something about it. If this amount of serious good-will could be transformed into organized, efficient action, there would be no danger for intergroup relations in the United States." (pg. 37)

Action Researchers do not believe apathy is the problem in our communities, but rather that people simply do not know how to make a difference or with whom they should work. Action Research brings the work to the community, rather than conducting it on the fringes. In the Dialogue framework, it is especially relevant to consider the goals of Critical Participatory Action Research which aims to go beyond active participation to a more nuanced understanding of practice and the invisible conditions that shape current actions and processes (Kemmis, McTaggart, and Nixon 2014). Understanding these conditions requires iterative, and oftentimes difficult, conversations which foster empathy. Again, the goal is not for library staff to become researchers, but rather to approach community conversations with a critical lens that allows library staff to understand and act on community needs, library deficits, and uncomfortable questions. The authors find the principles of Empowerment Evaluation and Participatory Action Research provide library staff with the necessary internal agency and targeted direction to allow them and their community partners to visualize the potential of their partnerships and actions.

\section{Research and Evaluation Procedures}

History. Community Dialogues began as a simple conversation to inform the design of the National Institutes of Health sponsored bilingual Discover Health/Descubre la Salud traveling library exhibition. Library staff eagerly contributed to the evolution of community conversations by using knowledge of their local communities to elicit collaborators who were instrumental in identifying both library and community needs around local health topics (Holland 2016). It was clear from these early Dialogues that a more robust evaluation of their efficacy and potential was needed. This section describes the research and evaluation of Community Dialogues that were part of the NASA Science Mission Directorate-funded NASA@ My Library program (Fitzhugh 2021) serving 75 public library locations, as well as the National Science Foundation-funded Project BUILD program serving 12 public library locations (Jocz 2020).

NASA@ My Library provided support to state library agencies and individual public libraries to provide NASA STEM content, programs, and activities to patrons. As part of Project BUILD, library staff created engineering checkout kits for patrons and formed partnerships with local engineers, who co-facilitated hands-on engineering programs for elementary-aged children. A key component of both programs was to provide service to groups typically underrepresented in STEM. Dialogues offered library staff an opportunity to increase their understanding of STEM expertise in their communities and to connect with potential partners serving diverse audience segments who may not take full advantage of library services.

Data Collection Methods and Sample. The specific goals and features of Dialogues are unique to individual libraries. Additionally, the overall approach to Dialogues evolved organically over time as more was learned by the project team about how libraries were thinking about, implementing, and using Dialogues. Therefore, NASA@ My Library and Project BUILD evaluators used an emergent qualitative approach to gain an understanding of library 
staffs' experience with and feelings about Dialogues, and the influence the Dialogues had on their work. The evaluators, which included Jen Jocz, chose this approach because it allows researchers to gain a deep understanding of participants' unique, personal views and experiences, and produce rich descriptions of these thoughts and experiences (Merriam \& Tisdell 2016), and to allow for flexibility in the types of data being collected. Evaluators obtained interviews and reflections about Dialogue activities from 40 public library staff across two projects. Library staff participating in the NASA@ My Library project were asked to complete a detailed reflection report after each Dialogue they facilitated. This report asked library staff to describe how they organized and facilitated Dialogues, including who they invited and what they hoped to achieve. They were also asked to reflect on the outcomes of the Dialogue, including key takeaways and next steps. Finally, library staff were prompted to think specifically about how they felt the Dialogue framework allowed them to reach underserved audiences and how they might improve upon this in future conversations. In total, 28 reflections reports were received from 27 public library systems across the United States between June 2017 and March 2019. The reflection report template is provided as an appendix.

Library staff from all six libraries participating in Project BUILD were interviewed about their experience with the project, including questions focused on their Dialogue experience, ways their library benefited from hosting Dialogues, and questions seeking suggestions for how the framework could be improved. A total of 13 library staff from six public libraries across the United States participated in virtual interviews between December 2019 and February 2020 (the interview instrument is provided as an appendix). In-person observations occurred at eight sites, with participants ranging from three individuals at the first site to 15 at the last.

Project BUILD and NASA@ My Library evaluators collected data from a diverse set of libraries ranging from small rural libraries to large urban library systems. Although the overarching aim of better understanding and reaching underserved audiences was common to all Dialogues, participating libraries had their own unique goals for their Dialogues. While convenience sampling was used for this study, the findings are strengthened by analyzing data collected over time from libraries representing a range of environments.

Data Analysis. Evaluators used Reflexive Thematic Analysis to gain a detailed look experiences of library staff engaging with and learning about their communities through Dialogues. This type of thematic analysis was selected because of its versatility, allowing themes to be constructed based on data rather than on predetermined, theoretical assumptions (Braun and Clarke 2019).

Reflection reports, open-ended survey responses, and interview transcripts were analyzed to identify themes describing experiences of library staff following the steps outlined by Braun and Clarke (2019). These steps involved (1) familiarization with the data, (2) creation of initial codes, (3) identification of broader patterns to generate initial themes, (4) review and refinement of themes, and (5) development of a detailed analysis of each theme. Although not included in the thematic analysis, observation notes were used to triangulate and provide additional examples of identified themes.

Results. Each NASA@My Library site was required to conduct at least one Dialogue in support of their program. Additional Dialogues were supported and encouraged. Based on results from the final survey, the majority of libraries (61 percent) hosted one Dialogue, with 39 percent hosting two or more.

Results from thematic analysis were organized into four themes describing library staffs' experiences of organizing, hosting, and reflecting on their Dialogues. Themes address the ways libraries benefited from hosting Dialogues 


\section{Community Dialogues to Enhance Inclusion and Equity in Public Libraries, continued}

as well as practical considerations for organizing and structuring Dialogues. A summary of the themes is shown in Figure 1 below.

\begin{tabular}{|c|c|c|}
\hline Theme 1 & $\begin{array}{l}\text { Community Dialogues bring } \\
\text { diverse groups together to } \\
\text { raise awareness of community } \\
\text { needs and how to better reach } \\
\text { undeserved audiences }\end{array}$ & $\begin{array}{l}\text { To ensure a variety of perspectives are } \\
\text { heard, library staff need to take steps to } \\
\text { bring diverse groups to the Dialogue. } \\
\text { This gives community members a } \\
\text { voice, allowing them to share their } \\
\text { thoughts and experiences. It also allows } \\
\text { library staff to better understand the } \\
\text { challenges faced by different groups in } \\
\text { their community, including challenges } \\
\text { that impact their ability to participate } \\
\text { in library programs and access library } \\
\text { resources. }\end{array}$ \\
\hline Theme 2 & $\begin{array}{l}\text { Community Dialogues } \\
\text { help identify shared goals } \\
\text { and ways participants can } \\
\text { work together to address } \\
\text { community needs }\end{array}$ & $\begin{array}{l}\text { Dialogues allow library staff to } \\
\text { communicate their library's goals and } \\
\text { commitment to serving their community, } \\
\text { while also giving community members } \\
\text { and organizations a chance to share } \\
\text { their assets and expertise. In this way, } \\
\text { Dialogue participants can identify } \\
\text { ways they can work together to address } \\
\text { community needs and better reach } \\
\text { underserved audiences. }\end{array}$ \\
\hline Theme 3 & $\begin{array}{l}\text { Reflecting and acting on key } \\
\text { takeaways from Community } \\
\text { Dialogues takes effort, but } \\
\text { can lead to changes in library } \\
\text { programming and practice }\end{array}$ & $\begin{array}{l}\text { The Dialogue is just the beginning; } \\
\text { the real work takes place after its } \\
\text { completion. Dialogues often raise } \\
\text { important topics and takeaways. } \\
\text { However, to make actual change, library } \\
\text { staff must reflect on what they heard } \\
\text { during the Dialogues, identify the key } \\
\text { lessons learned, and plan and execute } \\
\text { follow-up actions. }\end{array}$ \\
\hline Theme 4 & $\begin{array}{l}\text { A library's own community } \\
\text { should be taken into account } \\
\text { when considering the use of } \\
\text { Community Dialogues }\end{array}$ & $\begin{array}{l}\text { How a library approaches their Dialogue } \\
\text { depends on who they hope to engage } \\
\text { with, for what purpose, and how they } \\
\text { might connect with these individuals } \\
\text { or groups. Considering the format and } \\
\text { location of the Dialogue, taking time } \\
\text { to explain the purpose of the Dialogue } \\
\text { and build trust--creating a welcoming } \\
\text { environment--can make participants feel } \\
\text { more comfortable. }\end{array}$ \\
\hline
\end{tabular}

Figure 1. Dialogue Themes

Theme 1: Community Dialogues Bring Diverse Groups Together to Raise Awareness of Community Needs and How to Better Reach Undeserved Audiences. By bringing together a variety of individuals-for example, schoolteachers, government officials, local community groups, cultural organizations, and parents-community members shared thoughts and experiences with library staff that raised awareness of challenges their community faced. Library staff described how the Dialogues highlighted the challenges different groups in 
their community experience and how those challenges have impacted their ability to participate in library programs and access library resources. For example, library staff described learning about transportation challenges, language barriers, and the need to hold events at a time and place where they are most likely to engage their target audiences. They also received suggestions for how to market their services to the community better by using different publicity methods (e.g., social media vs. printed flyers) or promoting directly to specific groups in the community (e.g., parents or schools).

However, ensuring there are diverse perspectives represented at Dialogues relies on bringing different groups of people to the table and knowing how to reach them. Libraries can start to address this concern by employing existing contacts to gather ideas for individuals or specific groups. Publicizing the Dialogue through various communication channels can increase the library's reach for varied audiences who may use multiple platforms. Email can be a good first step, but following up with personal phone calls can add another layer of engagement and increase participation. Alternatively, libraries may choose to reach out with mailings on official letterhead requesting follow-up communication (e.g., a phone call or virtual teleconference). Some libraries also found that radio or social media was a better way to reach certain audiences. Using Dialogue attendees' own relationships and networks can further expand the reach of the library by asking who should also be at the table. These individuals can then be invited to future conversations or engaged in another way. The way the library reaches out will ultimately depend on the unique characteristics of their community, and the specific audience they are trying to reach. While networking is a time-consuming process, these are important steps to ensure diverse groups within the community attend and are heardeither at the same Dialogue or separately, ensuring the inclusion of a variety of perspectives. It is also very important to actively engage your participants, rather than passively distributing flyers and hope for participation. Discover Health libraries used this strategy and were more often satisfied with the results than libraries from other programs who had open invitations.

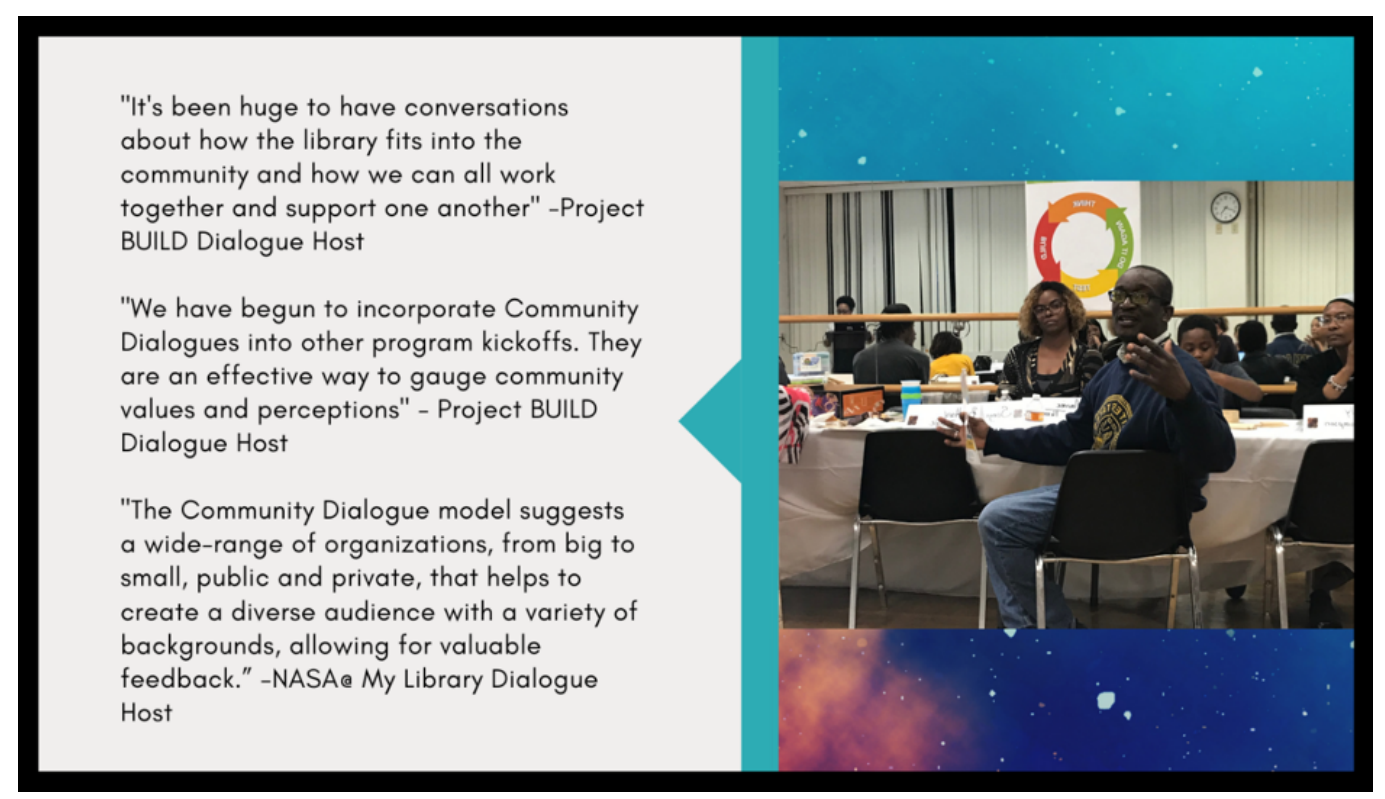

Figure 2. Feedback from Community Dialogue hosts (left) and a Dialogue at the Broward County African American Research Library (right), photo credit Beatrice Chavez, NCIL@SSI 


\author{
Community \\ Dialogues to Enhance \\ Inclusion and Equity \\ in Public Libraries, \\ continued
}

Theme 2: Community Dialogues Help Identify Shared Goals and Ways Participants Can Work Together to Address Community Needs. Dialogues provide an avenue for participants to begin identifying how they can work together to address the needs identified in the Dialogue process. Library staff can communicate their library's goals, exhibit commitment to serving their community, and highlight resources and services their libraries offer. Community leaders and organizations can similarly share their knowledge and discuss to partner with the library to better serve the community. (The Reflection section of this article provides an example of how one library implemented this theme.)

Libraries can identify partners for increased promotion and outreach as a shared goal. For example, community groups could advertise library resources to their members or physically bring them to the library for programs. Conversely, the library could bring programming or resources to audiences at a particular community organization. This can be especially useful in helping library staff reach out to specific audiences in their community, including underserved audiences.

Partnerships can be identified by library staff and Dialogue attendees that may lead to co-planning or co-presenting programs. For example, in the evaluation of Project BUILD, some libraries connected with local STEM experts (e.g., from local astronomy clubs, local universities, community colleges) who presented programs at the library or shared resources for library programming. Libraries may also identify community events to participate in or work with community partners to

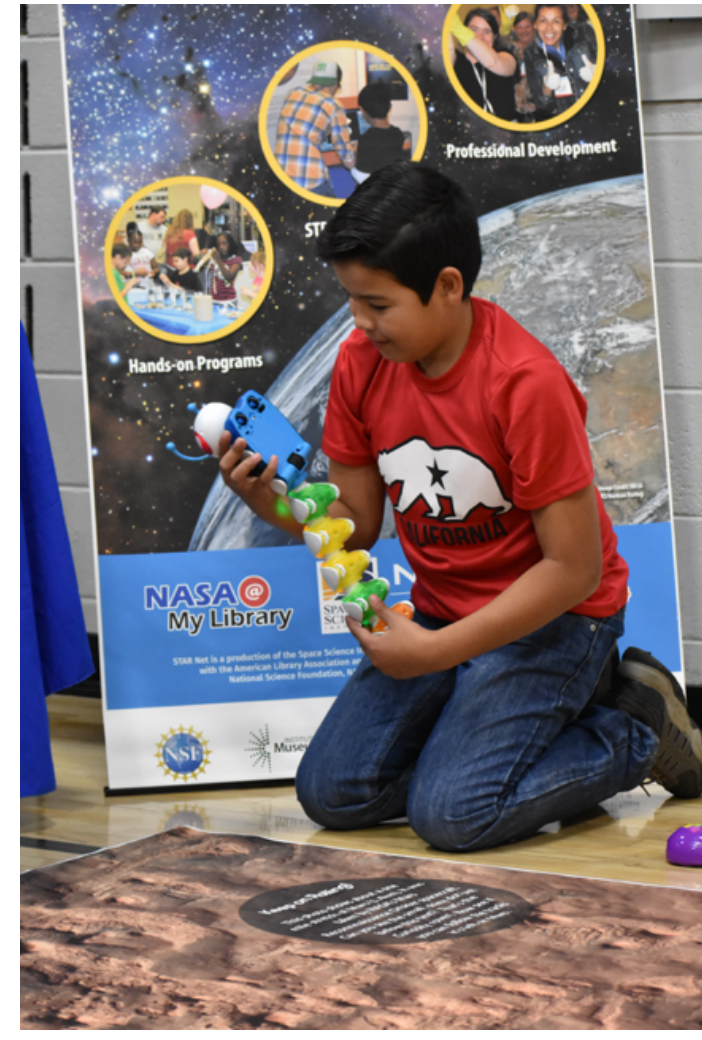

Figure 3. Over 30 organizations participated in the Yes!Fest event, providing engineering activities and opportunities to the community. Photo Credit Beatrice Chavez, NCIL@SSI arrange their own large-scale event.

As an example, one Project BUILD library hosted several Community Dialogues with the purpose of organizing a local science festival, an idea that originated at their first Dialogue. This YES!fest (Youth Engineering and Science Festival) included engineering partners and local STEM organizations. The festival attracted around 500 attendees, helping demonstrate to community members and organizations that the library is committed to supporting STEM learning in the community in ways that go beyond books and resources traditionally associated with a library. One library staff member explained that some in the community had "pigeonholed libraries as all about reading, and not necessarily reading to learn and learning on the larger scale" and the Dialogues and YES!fest "changed how people see us filling our role in the community."

Theme 3: Reflecting and Acting on Key Takeaways from Community Dialogues Takes Effort, But Can Lead to Changes in Library Programming and Practice. Key takeaways from Dialogues helped inform changes to library programming and 
practice. These takeaways included: a better understanding of the needs of the community, creation of new ways to conduct outreach, and the identification of potential community partners and collaborators. Libraries need to allot time to reflect on what they heard at the Dialogue and invest in intentional and realistic outcomes. These could include following up with potential partners, discussing what was learned with library directors or staff who can help move ideas forward, or planning more Dialogues and other strategies to gather additional feedback (e.g., surveys, community talk-back boards, etc.). One example from a Dialogue in support of Discover Health/Descubre la Salud highlighted a simple change that led to a stronger outcome. The library used a grant to build a Spanish-language children's nook but were disappointed it remain unused. A participant pointed out that the sign above the nook was in English, and it was not clear it was meant to be used by Spanish-speaking patrons. In a town where most Spanish speakers are recent immigrants from Mexico, an invitation to participate (including welcoming signage at the front door) was crucial to increase participation by the stakeholders who represented the local county Immigration Services Office. Other participants who worked closely with these populations agreed, and because of the conversation within the Dialogue, the library made signage and promotional items that explicitly welcomed Spanish speakers to the library and its reading nook, increasing participation from the intended audience.

Theme 4: A Library's Individual Community Should Be Taken into Account When Considering the Use of Community Dialogues. There is no one-size-fits-all approach to Dialogues. Libraries need to take into consideration the specific audiences they hope to engage with, for what purpose, and how they might connect with these individuals or groups. Working with, not for, these groups is crucial. The format or location of a Dialogue may not be immediately appealing or comfortable for some community members, especially those from underserved groups. Attendees may be frustrated and hesitant to participate in a Dialogue if they have previously taken part in similar conversations without seeing follow-up actions.

Before the Dialogue, libraries need to invest time identifying the groups they want to connect with and clearly explain the purpose of the Dialogue to members of those groups. This is often best accomplished through oneon-one interactions and may require multiple discussions to build trust and buy-in from the invitees. Similarly, steps should be taken to help participants feel comfortable during the Dialogue. These steps could include offering refreshments, providing established ground rules, and planning ample time at the beginning of the Dialogue for participants to network with each other. It may also be helpful to hold multiple Dialogues to foster trust between participants. This provides the opportunity for the library to share outcomes from previous Dialogues to demonstrate how participants' thoughts are being put into action.

It may be advisable to hold the conversation away from the library if the goal is to reach community members who do not feel comfortable in the space. Although there are advantages to libraries hosting their own Dialogues (such as communicating the library's commitment to serving their community), there are also benefits to taking advantage of community conversations already taking place. If a conversation is currently underway, there is no need to reinvent the wheel. In one example of this, a Project BUILD site was interested in learning more about youth and youth service organizations. Instead of hosting the Dialogue at their library, library staff incorporated it into one of their city's Youth Round Table events. The Youth Round Table is a municipal standing committee designed to address the needs of youth in the community. In the 


\author{
Community \\ Dialogues to Enhance \\ Inclusion and Equity \\ in Public Libraries, \\ continued
}

words of the library staff, this was an exciting venue to host their Dialogue because "the Youth Round Table gives the library access to a highly motivated group of people who can help us gain access to our target groups." By bringing the Dialogue to the group, the library staff were able to build a relationship dynamically and intentionally.

\section{Reflections and Promising Practices in Hosting Community Dialogues}

The following reflective firsthand account from Zachary Stier of the Erickson Public Library (Boone County, IA) highlights the process of planning and conducting a Dialogue, as well as next steps to ensure that the information gathered is acted upon. After the statement from Dr. Stier, we present observations collected by NASA@ My Library and the Project BUILD programs and evaluation teams.

In February of 2018, Erickson Public Library conducted our first Community Dialogue as part of the NASA@ My Library program. The objective for this dialogue was to meet with our local community stakeholders to discuss how this grant could positively impact STEM engagement in our community. In preparation for this dialogue, the following steps were taken:

1. Library staff, including the director and members of the board, met to discuss the library's current STEM programming for early learners through young adults. We focused on the diversity of current programs (such as the inclusion of STEM in reading programs, the use of technology, and diversified learning opportunities like science experiments or virtual and augmented reality).

2. We then completed a stakeholder audit to better understand and categorize current library partnerships with organizations, schools, and businesses. The initial stakeholder audit found that current library partners included public and private schools, an elderly volunteer program, local community college, area education, childcare, a local extension office, city council officials, and community-based services for persons with disabilities. The audit also helped us identify potential future partners outside of the community including state universities, state science center, early childhood association, public television, and the state library.

3. Finally, we sent invitations to existing and future partners based on the results of the stakeholder audit.

Now that we've conducted multiple successful Dialogues, we suggest that invitations be delivered as formal emails that include the following components: A purpose statement for the reason the Dialogue will be conducted; three to four working goals that will be accomplished by the Dialogue; the date for the Dialogue; and a 'hook' on why a stakeholder should participate in the Dialogue, including the value and expertise they can personally provide to the Dialogue. Other outcomes from this Dialogue included stakeholders reflecting and brainstorming on new STEM opportunities for early learners and adults in our community, many of which have come to fruition. Partners have committed to staying in contact with each other to make sure those ideas become a reality for our community.

I believe community dialogues are the fuel that sparks conversation on topics that can be uncomfortable, but necessary. Through this experience, stakeholders are responsible for identifying community concerns, to wrestle with difficult questions and realities, and to begin laying the foundation on what they aspire the community to be. 
Dialogue Promising Practices. The biggest question in getting started with Dialogue is "who to invite?" A suggestion from a librarian who has conducted multiple Dialogues was to follow in the footsteps of Mr. Rogers and "find the helpers." The Erickson Public Library took this advice to heart and invited a diverse set of community leaders, movers, and shakers to their three Dialogues. Their stakeholders included Iowa Science Center staff; Area Education staff; local STEM Council members; local community colleges; state library staff; principals, elementary grade teachers; Boone Schools Innovative School Leaders; Erickson city council members; Iowa Association for the Education of Young Children; various Iowa Library Associations; the Engineering Department at Iowa State University'; parents; and local television representatives.

In general, involving community leaders is an important step to facilitating dialogues that lead to actionable and achievable outcomes. These leaders can include school administrators, Parks and Recreation Department staff, WIC (Women, Infants, and Children) employees, Refugee Services, and other public officials. In addition to these obvious choices, participants can also include community movers and shakers that may not have an "official" title: people who know what is going on and are trusted voices who can represent the community. For example, homeschool influencers, a waitress at the local diner, a Little League coach, and retired NASA engineers factored heavily in recent Dialogues, showcasing the breadth of knowledge and commitment in these communities.

Dr. Stier suggests the following activities as options to make the most of everyone's time during an in-person Dialogue. Based on observations of many other Dialogues in the NASA@ My Library, Discover Health, and Project BUILD programs, the project team and evaluation partners support these suggestions:

- Host a tour: Use the opportunity of having new audiences in your building to provide a brief tour

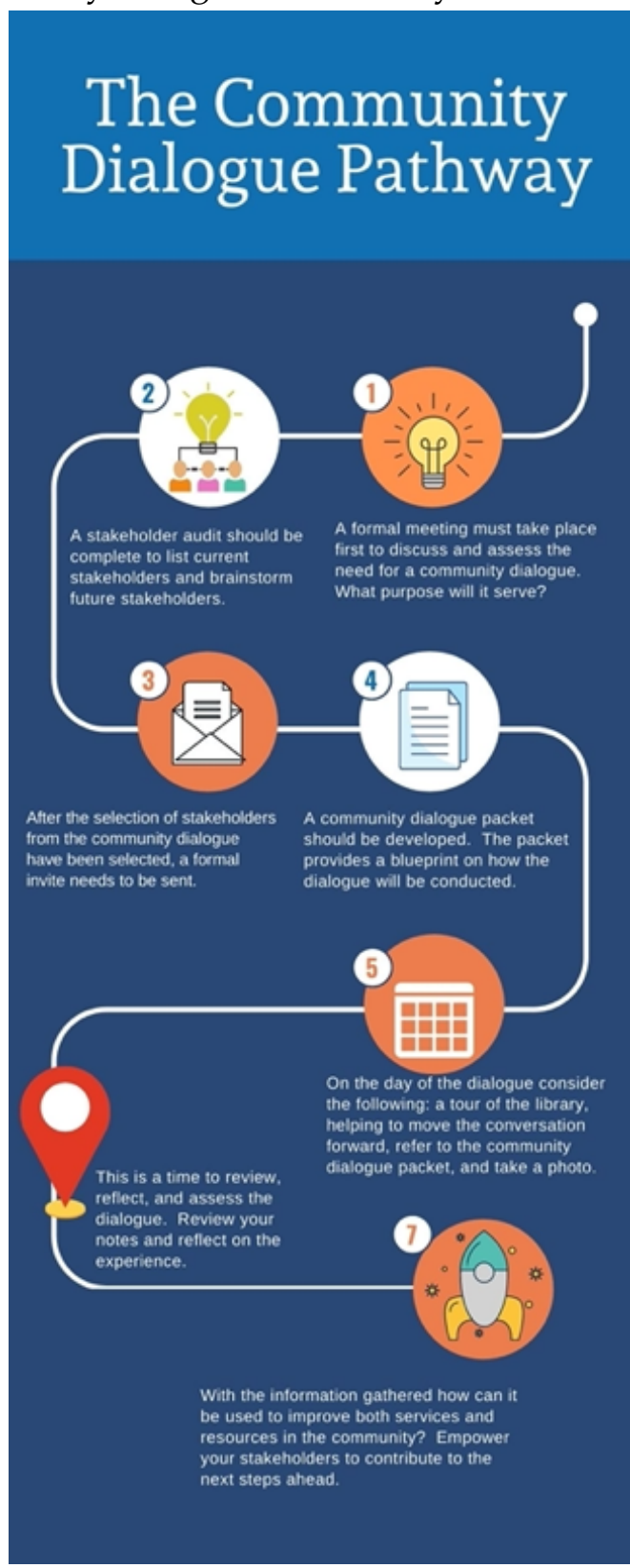

Figure 4. Infographic illustrating steps taken in The Community Dialogue Pathway. These steps aren't necessary synchronous. They are meant to be repeated and iterated on as necessary. Provided by Dr. Zachary Stier. of the library and discuss your services and resources. This can generate further conversation on how you and a stakeholder can develop a mutually beneficial partnership. 


\author{
Community \\ Dialogues to Enhance \\ Inclusion and Equity \\ in Public Libraries, \\ continued
}

- Keep the conversation moving and flexible: A Dialogue should not be scripted-encourage and allow the discussion to evolve organically. It is helpful to have prompt questions to move the conversation forward; however, if a stakeholder provides a response that helps to further the conversation, it is advised that you proceed with that new direction. This is a conversation, not a presentation!

- Provide a Community Dialogue packet: Send participants a digital or hard copy of relevant documents and ideas before the Dialogue. Also provide extra paper, writing materials, sticky notes, and snacks.

- Document: With permission, take a photo of stakeholders to aid in documentation of the Dialogue. Include comments and quotes from stakeholders. Consider using giant sticky notes that participants can take photographs of as they leave.

Recommended Dialogue Next Steps. The conversation does not end when the Dialogue does. In addition to writing notes and providing them to participants, ensure that the momentum of the Dialogue continues. It is extremely important that participants feel empowered to contribute to the next steps of the process, and feel like partners, not just invitees. Simple actions such as thank you letters or acknowledgement in a newsletter can increase buy-in and future participation. Consider the following questions when planning next steps:

- What comments and experiences were expressed that could generate a partnership opportunity in the future?

- Based on the topic of the Dialogue, in which areas are the library and other participant organizations doing well? Where might each organization benefit from support?

- Based on the responses from the Dialogue, what are action steps that can be taken by stakeholders to improve in these areas?

\section{Future Research Directions}

During the current global pandemic, libraries that have previously participated in Dialogues have begun to investigate the efficacy of conducting virtual Dialogues. Online Dialogues can, for example, focus on equitable programming in the face of the digital divide, service organizations working together to leverage their assets, and ways to support public schools. The authors recommend additional research on virtual Dialogues to understand if they can also be used to provide more equitable access to the conversations. The authors also recommend the collection of more quantitative data that investigates the nature of conversation programs currently happening in public libraries and other informal education organizations. The discussion of conversation models in the literature review provides a foundation for identifying possible targets. The authors are currently using the results of the NASA@ My Library and Project BUILD programs to create the observation and survey protocols for Dialogues that will be conducted in the new NSF funded STEAM Equity program. This program expands upon prior Dialogue work, with each library conducting three to five Dialogues in support of their goals of creating more equitable STEM/STEAM programming for their diverse patrons.

\section{Limitations}

The current study was limited to in-person observations at fewer than a dozen sites, and the remainder of data was gathered by post-Dialogue reflection forms and interviews. A more in-depth study using extensive observational data (including frequent follow-up interviews of both library staff and Dialogue participants) would provide a clearer picture of the role of Dialogues in promoting equitable practices to public libraries and their communities. 


\section{Conclusion}

Conversations with patrons are a common library practice, but Community Dialogues that purposefully seek out those unheard in the library space strengthen libraries' roles in engaging their entire community. Libraries can be empowered to move conversations beyond their walls to the whole community, while doing so in a way that is uncomplicated yet engaging. It does not matter if conversations are about increasing STEM programming, building community partnerships, or providing services to homeless patrons. What is important is having actionable conversations with diverse stakeholders and feeling confident the library can, and should, be at the center of these conversations. The following key aspects and lessons learned from conducting and evaluating Dialogues show how they are an invaluable tool for libraries at any stage of their engagement journey to take the next step in working with their communities.

- Dialogues are a flexible and effective tool to empower library staff to engage with diverse community members to search for the answers to their questions within their own community. They help library staff gain an awareness of what they can do in their own practice as well as through working together with diverse community members.

- Dialogues provide the foundation for strong relationship building, linking the library to community partners and organizations that they may not normally work with to impact a wider reach.

- Dialogues give libraries opportunities to increase their reach to underserved audiences or find solutions to a community issue.

- Dialogues are customizable and can be used by library staff for a wide range of topics, from social justice to environmental challenges, to reaching audiences not currently using library resources.

The inclusion of the Dialogue approach in the everyday work of public libraries has potential and power as an additional tool in libraries' missions to address issues of equity and access in individual communities. Libraries do not have to do this work alone. Community leaders and organizations are there to support you in this shared mission. Let them.

"The health of our civilization, the depth of our awareness about the underpinnings of our culture and our concern for the future can all be tested by how well we support our libraries." - Carl Sagan

NASA@ My Library is based upon work funded by NASA under cooperative agreement No. NNX16AE30A. Any opinions, findings, and conclusions or recommendations expressed in this material are those of NASA@ My Library and do not necessarily reflect the views of the National Aeronautics and Space Administration. Project BUILD is supported by the National Science Foundation under Grant Number DRL-1657593. Any opinions, findings, and conclusions or recommendations expressed in this material are those of the authors and do not necessarily reflect the views of the National Science Foundation.

\section{References}

Africawala, Jasmine. 2015. “Coffee \& Conversation." Programming Librarian. https://programminglibrarian.org/programs/coffee-conversation.

American Library Association. 2015. "Libraries Transforming Communities." Tools, Publications \& Resources. 2015. http:/ / www.ala.org/tools / librariestransform/libraries-transforming-communities.

Braun, Virginia, and Victoria Clarke. 2019. "Reflecting on Reflexive Thematic Analysis." Qualitative Research in Sport, Exercise and Health 11(4): 589-97. 


\author{
Community \\ Dialogues to Enhance \\ Inclusion and Equity \\ in Public Libraries, \\ continued
}

Brown, Chris. 2015. “Conversation-Based Librarianship: A New Potential for Community Knowledge." Journal of Library Administration 55(6): 483-93. https://doi.org/10.1080/01930826.2015.1054768.

Damasco, Ione T. 2019. "Creating Meaningful Engagement in Academic Libraries Using Principles of Intergroup Dialogue." in Libraries Promoting Reflective Dialogue in a Time of Political Polarization; edited by Andrea Baer, Elyysa Stern Cahoy, Robert, Schroeder; 13-32. Chicago, Illinois: Association of College and Research Libraries

Everett, Stephanie. 2018. "Visualizing the Silent Dialogue about Race: Diversity Outreach in an Academic Library." The Journal of Academic Librarianship 44(4) : 518-52

Everhart, Kevin, and Abraham Wandersman. 2000. “Applying Comprehensive Quality Programming and Empowerment Evaluation to Reduce Implementation Barriers." Journal of Educational and Psychological Consultation 11(2): 177-91.

Fetterman, David M. 1994. "Empowerment Evaluation." Evaluation Practice 15(1): 1-15. https:/ / doi.org/10.1016/0886-1633(94)90055-8.

Fetterman, David M., Liliana Rodríguez-Campos, Ann P. Zukoski, and Contributors. 2017. Collaborative, Participatory, and Empowerment Evaluation: Stakeholder Involvement Approaches. Guilford Publications. 2017.

Fetterman, David M., and Abraham Wandersman. 2005. Empowerment Evaluation Principles in Practice. Guilford Press.

Fitzhugh, Ginger, Jocz, Jen, Liston, Carrie. 2021. “NASA@ My Library Summative Report."ncil.spacescience.org/papers

Holland, Anne. 2016. "Front-End Evaluation: Report from the Discover Health/Descubre La Salud Community Dialogues." http://ncil. spacescience.org/images/papers/DH\%20Community\%20Dialogues $\% 20$ Report.pdf.

Holland, Anne. 2018. "A Community Dialogue Guide for Public Libraries." May, 2018. http:/ / www.starnetlibraries.org/wp-content/ uploads/2018/10/Community-Dialogue-Guide100418.pdf

Holland, Anne, and Dusenbery, Paul. 2018. "Community Dialogues in Informal Science Institutions." Informal Learning Review, no. 152: 21-24.

Honisett, Amy., Short, Rachel, and Schwab, Kate. 2018. "Building Community at the Library with Coffee and Conversation." OLA Quarterly 23(4): 20-25.

Jocz, Jen, Greller, Sarah. 2020. “Project BUILD Summative Evaluation Report." https://www.informalscience.org/project-build-summativeevaluation-report

Johnson, Sarah. "Partnering for Social Justice." In Social Justice and Activism in Libraries: Essays on Diversity and Change. Jefferson, North Carolina: McFarland \& Company, Inc, Publishers. 2019.

Johnston, Jamie. 2016. "Conversation-Based Programming and Newcomer Integration: A Case Study of the Språkhörnan Program at Malmö City Library." Library \& Information Science Research 38(1): 10-17. https://doi.org/10.1016/j.lisr.2016.02.001.

Johnston, Jamie, and Ragnar Audunson. 2019. "Supporting Immigrants' Political Integration through Discussion and Debate in Public Libraries." Journal of Librarianship and Information Science 51(1): 228-242.

Kemmis, Stephen, Robin McTaggart, and Rhonda Nixon. 2014. "Introducing Critical Participatory Action Research." In The Action Research Planner: Doing Critical Participatory Action Research, edited by Stephen Kemmis, Robin McTaggart, and Rhonda Nixon, 1-31. Singapore: Springer. https://doi.org/10.1007/978-981-4560-67-2 1. 
Lankes, David. "Beyond the Bullet Points: Bad Libraries Build Collections, Good Libraries Build Services, Great Libraries Build Communities." n.d. Accessed March 25, 2021. https: / / davidlankes.org/beyond-the-bulletpoints-bad-libraries-build-collections-good-libraries-build-services-greatlibraries-build-communities/.

Lewin, Kurt. 1946. "Action Research and Minority Problems." Journal of Social Issues 2, no. 4: 34-46. https://doi.org/10.1111/j.1540-4560.1946. tb02295.x.

Lor, Peter Johan. 2018. “Democracy, Information, and Libraries in a Time of Post-Truth Discourse." Library Management 39(5): 307-21.

Merriam, Sharan, and Tisdell, Elizabeth. 2016. Qualitative Research: A Guide to Design and Implementation (4th ed.). San Francisco, CA: Jossey Bass.

Museum of Science. 2021. "Coronavirus, a Community Conversation." https://www.mos.org/mos-at-home/town-hall/communityconversation-coronavirus

Patton, Michael Quinn. 1997. Utilization-focused Evaluation: The New Century Text (3rd ed.). Sage Publications, Inc.

Pew. 2013. "Library Services in the Digital Age." https://www.pewresearch.org/internet/2013/01/22/library-services/

Real, Brian, John Carlo Bertot, and Paul T. Jaeger. 2014. "Rural Public Libraries and Digital Inclusion: Issues and Challenges." Information Technology and Libraries (Online); Chicago 33, 1: 6-24.

Shtivelband, Annette, Wallander-Roberts, Amanda, and Jakubowski, Robert 2016. "STEM Equity Report, Datum Advisors, Research Evaluation Consulting." http://ncil.spacescience.org/images/papers/STEM-EquityInformal-Learning-Settings-122316.pdf

Secret, Mary, Audrey Jordan, and Janet Ford. 1999. "Empowerment Evaluation as a Social Work Strategy." Health \& Social Work 24 (2): 120-27.

Stufflebeam, Daniel L. 1994. "Empowerment Evaluation, Objectivist Evaluation, and Evaluation Standards: Where the Future of Evaluation Should Not Go and Where It Needs to Go." Evaluation Practice 15(3): 321-38.

Thorpe, Kirsten, and Monica Galassi. 2018. "Diversity, Inclusion \& Respect: Embedding Indigenous Priorities in Public Library Services." Public Library Quarterly 37(2): 180-94. https:/ / doi.org/10.1080/01616846.2018.1 460568.

Usherwood, Bob. 2016. Equity and Excellence in the Public Library: Why Ignorance Is Not Our Heritage. Abingdon: Taylor and Francis, Ashgate, Routledge. https:// doi.org/10.4324/9781315580173.

Whiteman, Eliza D., Roxanne Dupuis, Anna U. Morgan, Bernadette D'Alonzo, Caleb Epstein, Heather Klusaritz, and Carolyn C. Cannuscio. 2018. "Public Libraries As Partners for Health." Preventing Chronic Disease 15. https://doi.org/10.5888/pcd15.170392.

Williams, Amber, Erica Freudenberger, and Cindy Fesemyer. 2019. "Food for Thought: Feeding Mind and Body at Public Libraries." In Social Justice and Activism in Libraries: Essays on Diversity and Change. (pg. 39). Edited by Sue Epstein, Carol Smallwood, and Vera Gubnitskaia. Jefferson, North Carolina: McFarland \& Company, Inc, Publishers. 2019.

\section{Author Details}

Anne Holland, Community Engagement Manager, Space Science Institute: aholland@spacescience.org 
Community Dialogues to Enhance Inclusion and Equity in Public Libraries, continued
Jen Jocz, Senior Research Associate, Education Development Center: jjocz@edc.org

Stephanie Vierow-Fields, Education Coordinator, Space Science Institute: svfields@spacescience.org

Zachary Stier, Head of Children's Services, Ericson Public Library: zstier@boone.lib.ia.us

Lindsay Gypin, Data Services Librarian, University of North Carolina at Greensboro: lagypin@gmail.com

\section{Appendix A: Project BUILD Staff Interview Protocol}

1. In what ways has your library benefited from hosting Community Dialogues?

- Prompt: In what ways did the Community Dialogue strategy help your library better understand or meet the needs of your community (including reaching underserved audiences)?

- Prompt: Have you made new community partners as a result of the Community Dialogues? If so, how have you worked with them following the Community Dialogues?

2. In what ways, if at all, can you see your library using the Community Dialogue strategy in the future?

- Prompt: In what ways do you see any barriers or challenges that may prevent your library from hosting additional Community Dialogues?

3. Are there any resources that you would have found useful? Did you use the Community Dialogue Guide and, if so, what did you think (how did you use it, what did you find useful, what would you change)?

- Prompt: What suggestions would you offer other libraries interested in hosting Community Dialogues?

4. Aside from Community Dialogues, what other strategies did your library use to ensure Project BUILD activities met the needs of your community (for example, promotion or outreach to specific audiences, adaptations or modification to Project BUILD activities)?

\section{Appendix B: NASA@ My Library Dialogue Reflection Form}

- Date/Time

- Location

- Names of Organizers/Facilitator(s)

- Number of attendees

- What community groups or target audiences attended? What types of institutions were represented at your event?

- What strategies did you use to recruit participants (for example, a flyer, email, phone call, etc.)? Which were most effective?

- What did you hope to achieve for your library through the Community Dialogue event?

- In what ways did you involve NASA partners (e.g., Solar System Ambassadors, Night Sky Network)?

- If you had a PowerPoint presentation or other materials, please attach copies. If not indicated in the provided materials, please also list the questions that you asked at the Community Dialogue. 
- What strategies do you feel were most conducive to productive conversation?

- What were the key takeaways from the discussion?

- Which potential collaborations are you most excited about? Why are they particularly exciting?

- What are your next steps/plans to follow up with participants?

- In what ways do you feel that the Community Dialogue model is effective for reaching underserved audiences? What would you do differently to better reach underserved audiences? 